the hydrolysis of the latter as much as possible. The analytical results show small variations which may be attributed to a slight hydrolysis. In seven experiments the percentages of zirconium dioxide present were as follows: $44.91 ; 44.84 ; 45.38 ; 45.79 ; 46.32 ; 45.47 ; 44.06$. An increase in zirconium oxide indicates increased hydrolysis. The percentage of the dioxide in the substance $(\mathrm{ZrO})_{3}\left(\mathrm{C}_{6} \mathrm{H}_{5} \mathrm{O}_{7}\right)_{2}$ is 45.80 . The precipitate is, therefore, apparently the normal zirconyl citrate. It must be borne in mind that the loss of some zirconia is very difficult to avoid when it is ignited in the presence of organic matter.

When the zirconyl chloride solution was boiled for some time so as to bring about a far-reaching hydrolysis and the citric acid added to this, the resulting percentages of zirconium dioxide in four experiments were: $57.19 ; 57.37 ; 57.21 ; 57.20$. These show a fairly definite resulting compound. The basic zirconyl citrate $3 \mathrm{ZrO}(\mathrm{OH})_{2} .(\mathrm{ZrO})_{3}\left(\mathrm{C}_{6} \mathrm{H}_{5} \mathrm{O}_{7}\right)_{2}$, contains $57.13 \%$ of the dioxide.

\title{
Summary
}

1. No double citrate as reported by Harris was formed, nor was a double citrate with potassium obtained.

2. Zirconyl citrate, $(\mathrm{ZrO})_{3}\left(\mathrm{C}_{6} \mathrm{H}_{5} \mathrm{O}_{7}\right)_{2}$, was prepared. It is easily hydrolyzed.

3. Basic zirconyl citrate, $3 \mathrm{ZrO}(\mathrm{OH})_{2}(\mathrm{ZrO})_{3}\left(\mathrm{C}_{6} \mathrm{H}_{5} \mathrm{O}_{7}\right)_{2}$, was also prepared.

Chapet, Hili, North Carolina

[CONTRIBUTION FROM THE ChEMICAL LABORATORY OF MCGML, UNIVERSITY]

\section{VAPOR DENSITIES AT LOW PRESSURES AND OVER AN EX- TENDED TEMPERATURE RANGE. I. THE PROPERTIES OF ETHYLENE OXIDE COMPARED TO OXYGEN COMPOUNDS OF SIMILAR MOLECULAR WEIGHT}

\author{
By O. MAass and E. H. Boomer
}

Received June 15,1922

\section{Introduction}

This paper is the first of a series dealing with the vapor densities of a number of organic compounds. The densities dealt with are measured over a considerable temperature range and at various pressures with a view to bringing out the effect of the attracting forces of the molecules for one another and comparing other physical properties which are also influenced by these forces. Ethylene oxide is one of the substances which has been examined so far and since a number of its physical properties had to be determined, these are included in this paper together with those 
of methyl ether, acetaldehyde and ethyl alcohol for the purpose of comparing oxygen containing compounds of similar molecular weight. The investigation was also extended to cover the tendency of ethylene oxide toward oxonium-compound formation. The vapor densities of ethylene oxide were determined over the temperature range $14^{\circ}$ to $100^{\circ}$ and the pressure range 0 to 1 atmosphere (the primary object of the research) and are described last of all.

Preparation of the Ethylene Oxide. -The ethylene oxide was prepared in a similar manner to that described by Wurtz ${ }^{1}$ in which ethylene chlorohydrin is decomposed by concentrated sodium hydroxide.

$$
\mathrm{ClCH}_{2} \mathrm{CH}_{2} \mathrm{Cl}+\mathrm{NaOH}=\mathrm{CH}_{2} \mathrm{OCH}_{2}+\mathrm{NaCl}+\mathrm{H}_{2} \mathrm{O}
$$

The chlorohydrin used was formed by the action of chlorine on ethylene dissolved in water in the manner described by Gomberg. ${ }^{2}$ Solutions of $10 \%$ chlorohydrin were obtained without the formation of an appreciable amount of dichloro-ethane and were easily concentrated to $70 \%$ by a combination of distillation and salting out, developed from Gomberg's data.

This $70 \%$ solution was placed in a distilling flask fitted with a dropping funnel containing conc. sodium hydroxide solution. The side tube of the flask was glass sealed to a condensing apparatus consisting of a vertical glass coil ending in a cylindrical bulb with a side tube serving as exit. The condensing apparatus was built of such a size that it could be wholly immersed in a large sized Dewar flask. As suggested by Wurtz, in the first experiment a calcium chloride tube was introduced between the distilling flask and the condenser in an endeavor to dry the ethylene oxide, but an easily noticed reaction occurred, ethylene chlorohydrin and calcium hydroxide being formed. The attempt to dry the gas in this manner was given up.

Salt and ice served as the cooling liquid and the flow of sodium hydroxide into the flask was so regulated that no odor of ethylene oxide could be detected at the exit. The reaction was allowed to proceed to completion, considerable sodium chloride being precipitated in the last stages. Finally, the flask was gradually warmed to about $80^{\circ}$ to remove the last of the ethylene oxide. The salt-and-ice cooling mixture was replaced by one of solid carbon dioxide and ether, and air was drawn through the apparatus to remove the ethylene oxide vapor, previous to sealing the bulb and contents to the fractionating apparatus. Care was taken to cool the distilling flask properly before air was drawn through, as a violent explosion occurred on one occasion when this precaution was not taken.

The principal impurity in the ethylene oxide prepared in this way is water. Drying agents cannot be employed for the removal of the latter on account of the chemical activity of the ethylene oxide, which was found to react with each drying agent tried. Resort was had to fractional distillation at low temperatures and pressures. The fractionating apparatus was an all-glass system consisting of a mercury manometer, a mercury vacuum pump and several cylindrical bulbs of about $50 \mathrm{cc}$. capacity, each bulb having its individual stopcock. The bulb containing the ethylene oxide was surrounded by a mixture of solid carbon dioxide and ether, placed in a Dewar flask, and the whole system evacuated for several

${ }^{1}$ Wurtz, Ann. chim. phys., [3] 69, 317 (1863).

2 Gomberg, Thrs Journal, 41, 1414 (1919). 
hours, the vapor pressure of ethylene oxide at this temperature being about $1 \mathrm{~mm}$. The pump was shut off, one of the empty bulbs was surrounded by a mixture of solid carbon dioxide and ether $\left(-78^{\circ}\right)$ and the bulb containing the ethylene oxide maintained at $-45^{\circ}$. A slow distillation commenced and was allowed to proceed until only a crystalline solid (hydrate of ethylene oxide) was left in the original bulb, which was then sealed off. The vapor pressure of the distillate was measured at $0^{\circ}$ and found to be $420 \mathrm{~mm}$. of mercury. The process was then repeated unti1 $3 / 4$ of the first distillate had passed into a third bulb. The vapor pressure was again measured at $0^{\circ}$, and found to be $493.1 \mathrm{~mm}$., which on repeated distillation remained unchanged both for distillate and residue. Nevertheless, at least one additional distillation was made in every case, although no change in the above vapor pressure was observed.

Accurate observations of the boiling point showed it to be $10.73^{\circ}$, with an error of less than $0.03^{\circ}$. That the amount of water in the material prepared in this manner is inappreciable was shown later by molecular weight determinations and conductivity measurements, and by the inertness of the liquid toward metallic sodium. This boiling point is nearly $2^{\circ}$ lower than that found by other investigators, possibly due to the contamination of their samples with water or chlorohydrin, since it was shown that the presence of these would raise the boiling point.

Pure ethylene oxide was found to be a non-conductor, but would dissolve salts such as sodium chloride and potassium nitrate and form conducting solutions, the latter salt being the more soluble and forming the better conducting solution. Water solutions of ethylene oxide also were found to be conducting, but it is possible that the conductivity is due to the formation of glycollic acid which, according to Wurtz, ${ }^{1}$ is formed from a mixture of ethylene oxide and water in the presence of platinum black. On long treatment of pure metallic sodium with ethylene oxide, the sodium was apparently acted upon at the surface, and the vaporpressure of the ethylene oxide was raised slightly. Upon evaporation of the ethylene oxide a solid substance was deposited upon the walls of the vessel in small amount; this was probably the complex polymer of ethylene oxide discovered by Wurtz. ${ }^{3}$ 'There appeared to be some decomposition, as the surface of the sodium became brown in color, but the brown layer was infusible up to $150^{\circ}$.

Phosphorus pentoxide reacted with ethylene oxide vapor and could not be used as a drying agent, free carbon and water being among the products of the reaction. The property of ethylene oxide of precipitating the hydroxides of metals such as calcium, magnesium, cadmium, etc., from solutions of their salts was investigated with the object of using the reaction as a means of measuring the amount of hydrolysis of these salts.

${ }^{3}$ Wurtz, Bull. soc. chim., [2] 29, 530 (1878). 
It was found, however, that the reaction was very slow, did not proceed to completion and so could not be used for this purpose.

The Vapor Pressure of Ethylene Oxide.-The vapor pressure was determined with the apparatus described above over the range of temperature $-57^{\circ}$ to $12.8^{\circ}$. The temperatures below $0^{\circ}$ were measured by means of a platinum resistance thermometer, those above $0^{\circ}$ by a standardized mercury thermometer, and both are correct to $0.1^{\circ}$. An ether bath, described elsewhere, ${ }^{4}$ whose temperature could be maintained constant to within $0.05^{\circ}$ at any desired temperature above $-78^{\circ}$, was employed. The manometer readings, corrected for the temperature of the mercury, may be taken as correct to within $0.2 \mathrm{~mm}$. In Table I are given the values thus obtained (see Fig. 1).

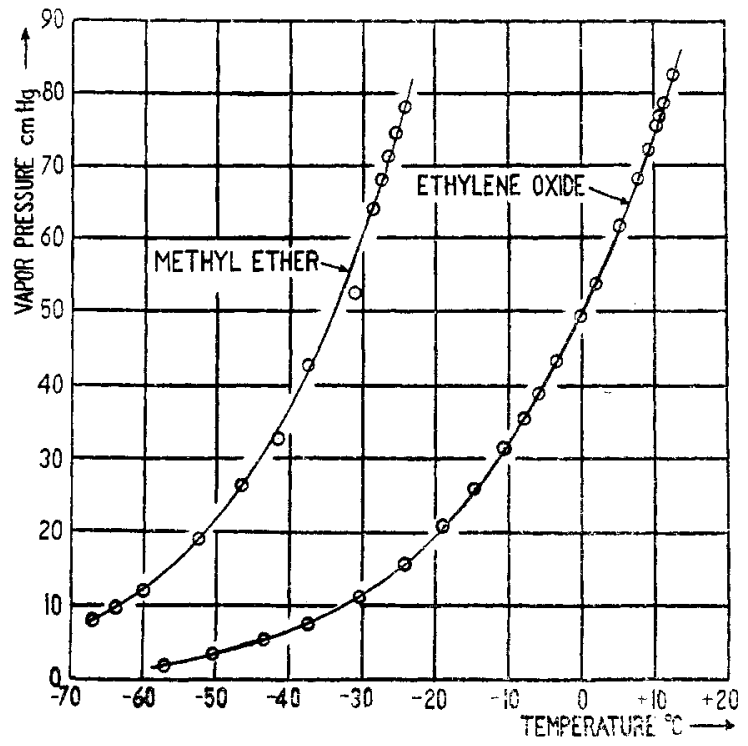

Fig. 1.

The value of the boiling point given by the vapor pressure curve is $10.73^{\circ}$, agreeing with the first determination. The molar heat of vaporization, calculated by means of the equation of Clausius and Clapeyron, has a value of $6.00 \mathrm{~kg}$. cal., as compared to the value of 6.1 found by Berthelot ${ }^{5}$ by direct measurement. Trouton's constant is found to be 21.14 in close agreement with the value 21.0 for most liquids.

The Freezing Point of the Ethylene Oxide.-The freezing point of ethylene oxide, sealed in a small glass bulb, was determined in a petroleum ether bath using liquid air as the cooling agent, ${ }^{6}$ and was found to be

4 Maass and McIntosh, This Journal, 35, 536 (1913).

5 Berthelot, Compt. rend., 93, 185 (1881).

6 Maass and MeIntosh, This Journal, 36, 738 (1914). 
TABLE I

VAPOR PRESSURES

\begin{tabular}{|c|c|c|c|}
\hline \multicolumn{2}{|c|}{ Ethylene Oxide } & \multicolumn{2}{|c|}{ Methyl Ether } \\
\hline Temp. & Press. & Temp. & Press. \\
\hline${ }^{\circ} \mathrm{C}$ & $\mathrm{Cm}$. of $\mathrm{Hg}$ & ${ }^{\circ} \mathrm{C}$ & $\mathrm{Cn}$. of $\mathrm{Hg}$ \\
\hline-57.0 & 1.95 & -66.9 & 7.77 \\
\hline-50.3 & 3.27 & -63.8 & 9.52 \\
\hline-43.4 & 5.09 & -60.0 & 11.96 \\
\hline-37.4 & 7.45 & -52.4 & 18.92 \\
\hline-30.4 & 11.06 & -46.6 & 26.17 \\
\hline-24.2 & 15.57 & -41.4 & 32.62 \\
\hline-18.9 & 20.75 & -37.3 & 42.66 \\
\hline-14.6 & 25.76 & -30.9 & 52.40 \\
\hline-10.5 & 31.27 & -28.5 & 63.94 \\
\hline-7.8 & 35.28 & -27.2 & 67.92 \\
\hline-5.8 & 38.82 & -26.3 & 71.15 \\
\hline-3.3 & 43.17 & -25.3 & 74.50 \\
\hline 0.0 & 49.31 & -24.1 & 78.17 \\
\hline 2.0 & 53.70 & $\ldots$ & $\ldots$ \\
\hline 5.3 & 61.58 & $\ldots$ & . \\
\hline 7.9 & 68.22 & $\ldots$ & . \\
\hline 9.4 & 72.27 & $\ldots$ & . \\
\hline 10.6 & 75.66 & $\ldots$ & . \\
\hline 11.0 & 76.80 & $\ldots$ & . \\
\hline 11.6 & 78.65 & & \\
\hline 12.8 & 82.49 & & . . \\
\hline
\end{tabular}

$-111.3^{\circ}$. Complete melting or solidification took place within a temperature interval of a few tenths of a degree, an indication of the purity of the substance.

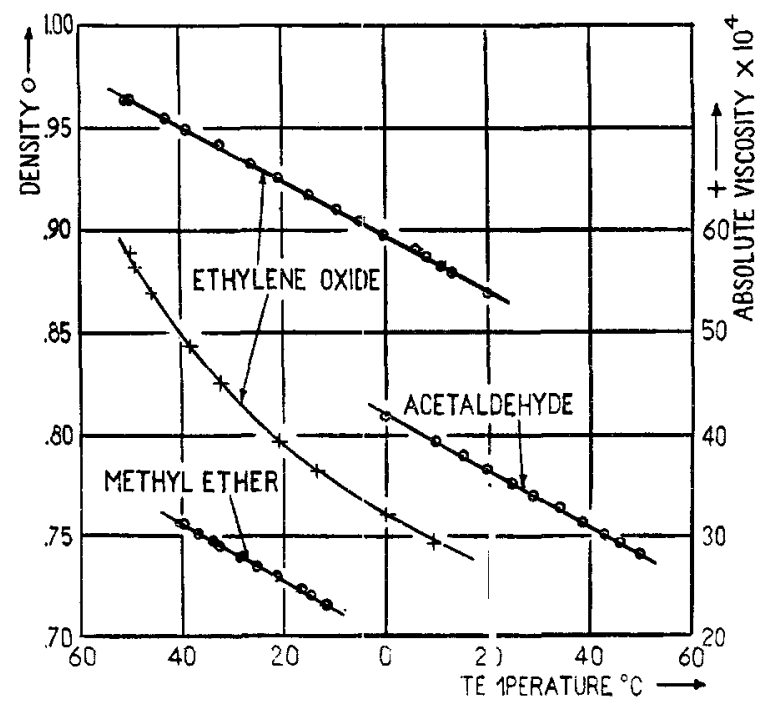

Fig. 2. 
The Density of Ethylene Oxide.-The densities at various temperatures were determined by the dilatometer method, as described in a previous paper, ${ }^{7}$ the method being accurate to $0.02 \%$. In Table II will be found the values of density thus obtained and in Fig. 2 is a reduced copy of the density curve used in later work.

TABLE II

DENSITIES

\begin{tabular}{cccccc}
\multicolumn{2}{c}{ Ethylene oxide } & \multicolumn{2}{c}{ Methyl ether } & \multicolumn{2}{c}{ Acetaldehyde } \\
Temp. & Density & Temp. & Density & Temp. & Density \\
${ }^{\circ} \mathrm{C}$. & & ${ }^{\circ} \mathrm{C}$. & & ${ }^{\circ} \mathrm{C}$. & \\
-51.1 & 0.9641 & -40.5 & 0.7565 & 0.1 & 0.8090 \\
-50.1 & 0.9631 & -39.7 & 0.7557 & 10.0 & 0.7970 \\
-43.4 & 0.9548 & -36.7 & 0.7507 & 15.0 & 0.7904 \\
-39.2 & 0.9490 & -34.0 & 0.7473 & 20.0 & 0.7833 \\
-32.5 & 0.9411 & -32.5 & 0.7447 & 25.0 & 0.7761 \\
-26.2 & 0.9320 & -28.6 & 0.7393 & 29.0 & 0.7701 \\
-21.1 & 0.9252 & -25.1 & 0.7374 & 34.1 & 0.7636 \\
-15.0 & 0.9170 & -21.4 & 0.7289 & 38.8 & 0.7561 \\
-9.6 & 0.9101 & -16.5 & 0.7220 & 43.0 & 0.7502 \\
-5.0 & 0.9039 & -14.7 & 0.7201 & 46.0 & 0.7468 \\
-0.3 & 0.8974 & -11.5 & 0.7154 & 50.0 & 0.7409 \\
5.8 & 0.8896 & $\ldots$. & $\ldots$. & $\ldots$ & $\ldots$ \\
8.0 & 0.8862 & $\ldots$. & $\ldots$ & $\ldots$ & $\ldots$ \\
10.5 & 0.8826 & $\ldots$. & $\ldots$ & $\ldots$ & $\ldots$ \\
13.4 & 0.8974 & $\ldots$. & $\ldots$ & $\ldots$ & $\ldots$ \\
20.0 & 0.8694 & $\ldots$. & $\ldots$ & $\ldots$ & $\ldots$
\end{tabular}

The density at the boiling point was found to be 0.8827 and from this value 49.85 was obtained as the molecular volume of ethylene oxide at that temperature.

The Surface Tension of Ethylene Oxide.-The determination of surface tension was made with the capillary-tube apparatus as designed by Richards. ${ }^{8}$ It was filled in the same manner as was the dilatometer and was, therefore, free from air. The density of the liquid ethylene oxide was obtained from the density curve and the density of the ethylene oxide vapor calculated from the vapor-pressure curve. The molecular surface energy was calculated in the usual manner and the values for it and for the surface tension are given in Table III. The Ramsay and Shield's constant was found to be 1.79 , indicating association. The total surface energy was calculated to be 73.2 dynes. The values of surface tension and molecular surface energy are shown in Fig. 3.

The Viscosity of Ethylene Oxide.-Due to the low boiling point of ethylene oxide, the measurement of its viscosity presented certain experimental difficulties. The following apparatus, illustrated in Fig. 4, was therefore devised and can be used in all such cases.

${ }^{7}$ Maass and Wright, ThIs Journal, 43, 1103 (1921).

${ }^{8}$ Richards, ibid., 37, 1656 (1915). 
TAFLE III

Surface Tenston and Molecular Surface Energy

\begin{tabular}{rcccccc}
\multicolumn{7}{c}{ Ethylene oxide } \\
$c_{\mathrm{C}}$ & $h$ & $d_{\mathrm{i}}$ & $d_{\mathrm{g}}$ & $d_{1-d_{\mathrm{g}}}$ & $(\mathrm{Fm}) \cdot / 3$ \\
-52.0 & 2.86 & 0.9658 & 0.0001 & 0.9657 & 36.4 & 464.6 \\
-50.8 & 2.80 & 0.9644 & 0.0001 & 0.9643 & 35.5 & 453.5 \\
-43.4 & 2.76 & 0.9547 & 0.0002 & 0.9545 & 34.8 & 447.7 \\
-39.2 & 2.69 & 0.9491 & 0.0002 & 0.9489 & 33.8 & 436.5 \\
-32.5 & 2.63 & 0.9403 & 0.0003 & 0.9400 & 33.8 & 426.3 \\
-26.2 & 2.58 & 0.9320 & 0.0004 & 0.9316 & 31.9 & 417.0 \\
-21.1 & 2.13 & 0.9252 & 0.0005 & 0.9247 & 31.1 & 408.6 \\
-15.0 & 2.48 & 0.9171 & 0.0007 & 0.9164 & 30.3 & 400.3 \\
-9.6 & 2.41 & 0.9100 & 0.0009 & 0.9091 & 29.2 & 387.9 \\
-5.0 & 2.36 & 0.9038 & 0.0011 & 0.9027 & 28.4 & 378.8 \\
-0.3 & 2.30 & 0.8976 & 0.0012 & 0.8963 & 27.4 & 367.3 \\
5.8 & 2.26 & 0.8895 & 0.0016 & 0.8879 & 26.8 & 361.4 \\
10.5 & 2.20 & 0.8866 & 0.0019 & 0.8857 & 25.9 & 353.8 \\
13.3 & 2.16 & 0.8826 & 0.0021 & 0.8805 & 25.4 & 344.3 \\
20.0 & 2.09 & 0.8707 & 0.0029 & 0.8679 & 24.3 & 332.4
\end{tabular}

$\begin{array}{lll}-42.0 & 2.12 & 0.7582 \\ -40.2 & 2.09 & 0.7556 \\ -39.0 & 2.07 & 0.7540 \\ -37.3 & 2.05 & 0.7515 \\ -35.1 & 2.03 & 0.7485 \\ -33.0 & 2.00 & 0.7456 \\ -30.9 & 1.19 & 0.7426 \\ -29.9 & 1.98 & 0.7412 \\ -26.4 & 1.94 & 0.7363 \\ -24.0 & 1.90 & 0.7329 \\ -20.0 & 1.88 & 0.7273 \\ -17.3 & 1.84 & 0.7236 \\ -15.1 & 1.80 & 0.7205 \\ -13.1 & 1.78 & 0.7194 \\ -10.6 & 1.76 & 0.7176\end{array}$

Methyl ether

$\begin{array}{llll}0.0010 & 0.7572 & 21.3 & 328.5 \\ 0.0011 & 0.7545 & 21.0 & 324.5 \\ 0.0012 & 0.7528 & 20.8 & 322.1 \\ 0.0013 & 0.7502 & 20.5 & 318.1 \\ 0.0014 & 0.7471 & 29.1 & 314.5 \\ 0.0016 & 0.7440 & 19.8 & 309.4 \\ 0.0017 & 0.7409 & 19.5 & 305.1 \\ 0.0018 & 0.7394 & 19.3 & 303.0 \\ 0.0021 & 0.7342 & 18.9 & 297.7 \\ 0.0023 & 0.7306 & 18.4 & 291.5 \\ 0.0027 & 0.7246 & 17.9 & 283.9 \\ 0.0030 & 0.7206 & 17.5 & 278.6 \\ 0.0033 & 0.7172 & 17.2 & 274.5 \\ 0.0035 & 0.7159 & 16.9 & 270.1 \\ 0.0037 & 0.7139 & 16.5 & 265.4\end{array}$

Acetaldehyde

$\begin{array}{rrrrrrr}0.1 & 2.20 & 0.8112 & 0.0007 & 0.8105 & 23.9 & 343.0 \\ 10.0 & 2.10 & 0.7973 & 0.0011 & 0.7962 & 22.4 & 324.5 \\ 15.0 & 2.06 & 0.7901 & 0.0014 & 0.7887 & 21.8 & 318.1 \\ 20.0 & 2.02 & 0.7831 & 0.0018 & 0.7813 & 21.2 & 310.8 \\ 250 & 1.98 & 0.7760 & 0.0021 & 0.7739 & 20.6 & 303.6 \\ 29.0 & 1.95 & 0.7704 & 0.0024 & 0.7680 & 20.1 & 298.4 \\ 34.1 & 1.90 & 0.7632 & 0.0027 & 0.7605 & 19.3 & 289.1 \\ 38.8 & 1.85 & 0.7565 & 0.0031 & 0.7534 & 18.7 & 280.9 \\ 43.0 & 1.79 & 0.7504 & 0.0034 & 0.7470 & 18.0 & 271.2 \\ 46.0 & 1.77 & 0.7461 & 0.0037 & 0.7424 & 17.6 & 266.7 \\ 50.0 & 1.73 & 0.7404 & 0.0040 & 0.7364 & 17.0 & 259.2\end{array}$


An ordinary Ostwald viscosimeter $A$, had 2 tubes, $G$ and $D$, sealed to it, one of which, $D$, was about $3 \mathrm{~cm}$. in diameter and $50 \mathrm{cc}$. in volume. The reservoir $D$ was connected, through the $\operatorname{tap} \mathrm{C}$, to another and larger reservoir $B$. The tube $G$ was also connected to the apparatus containing ethylene oxide at $\mathrm{E}$. All parts of this apparatus were thoronghly cleaned and dried before they were assembled.

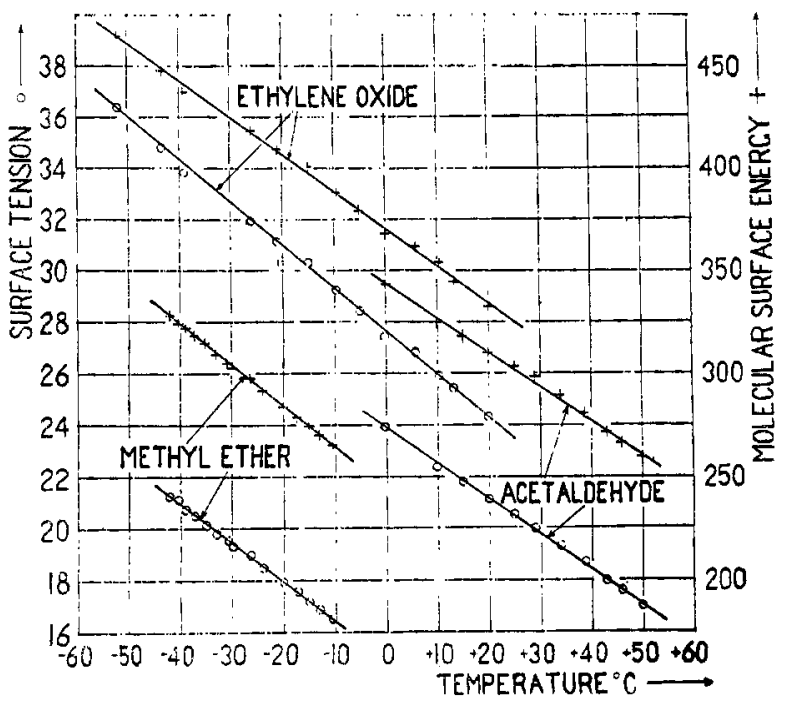

Fig. 3.

The apparatus was evacuated and heated during evacuation, in order to drive off any water vapor held on the surface of the glass. A known gas volume, at a known temperature and pressure, of ethylene oxide vapor was measured in the manner de-

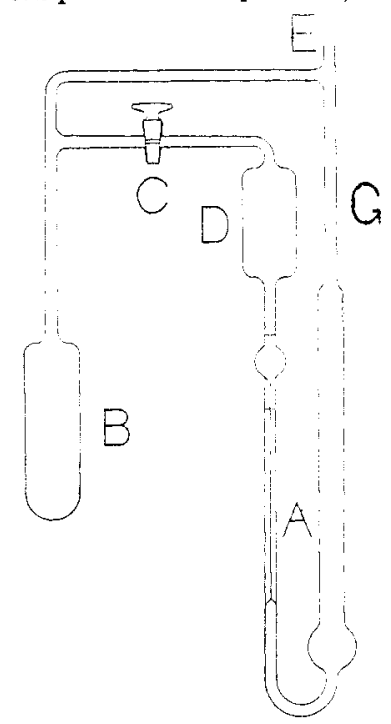

Fig. 4. scribed later on in the molecular-weight determinations, and was condensed in the viscosimeter. This was repeated several times until a sufficient quantity of liquid had been collected. Air, dried by passage over phosphorus pentoxide, was allowed to enter the apparatus until the pressure was very nearly atmospheric, and the tap above $\mathrm{E}$ was then closed and kept closed until the viscosity determinations were finished. A temperature bath, described previously, was placed around $A$ and the time of fall of the ethylene oxide in the viscosimeter determined in the following manner. The tap $\mathrm{C}$ was closed and the reservoir $B$ gently warmed with a smoky flame. This increased the pressure in $A$ and caused the ethylene oxide to move from $F$ up into $K$. As soon as the liquid had passed the upper etched mark on the viscosimeter, the flame was removed from $B$ and the tap $C$ was opened thus equalizing the pressure and allowing the liquid to fall, the time of fall being obtained.

When the required temperature range had been covered, the ethylene oxide was distilled back into its container and the viscosimeter was separated from the rest of the apparatus, cleaned, dried and weighed ac- 
curately. The weight of ethylene oxide was calculated, corrections for the gas laws as determined later being applied, and was found to be $3.6459 \mathrm{~g}$. At $9.3^{\circ}$, the upper limit of the range of temperature covered, the density of ethylene oxide was from the density curve 0.8846 , making the volume of the ethylene oxide at this temperature $4.1217 \mathrm{cc}$. No correction for the ethylene oxide vapor was necessary because the much greater proportion of air made the amount of ethylene oxide present as vapor, negligible. The density of water at $0^{\circ}$ being taken as 0.99987 , the weight of a volume of water at $0^{\circ}$ equal to the above volume of ethylene oxide was $4.1212 \mathrm{~g}$. Exactly this weight of water was added to the viscosimeter and its time of fall at $0^{\circ}$, as determined in the ordinary way, was found to be 178.5 seconds. The calculation was repeated for the volume of the ethylene oxide at $-49^{\circ}$ and the time of the fall of the corresponding volume of water at $0^{\circ}$ was found to be 177.6 seconds. These two times were plotted against the corresponding temperatures and hence the times for all intermediate temperatures were thus obtained.

In Table IV will be found the various values of the absolute viscosity, and in Fig. 2 they are plotted.

\begin{tabular}{|c|c|c|c|c|c|}
\hline \multirow{4}{*}{$\begin{array}{l}\text { Temp. } \\
{ }^{\circ} \mathrm{C} . \\
-49.8\end{array}$} & \multicolumn{4}{|c|}{ TABLE IV } & \multirow[b]{3}{*}{$\begin{array}{l}\text { Absolute } \\
\text { Viscosity }\end{array}$} \\
\hline & & $\operatorname{Scosit} Y$ & ETHYLENE & OXIDE & \\
\hline & $\begin{array}{r}\text { Tim } \\
\text { Ethylene }\end{array}$ & $\begin{array}{l}\text { fall of } \\
\text { e Water }\end{array}$ & Density & Volume & \\
\hline & Sec. & Sec. & & $\begin{array}{r}\mathrm{Cc} \\
\mathrm{T}\end{array}$ & c. p. \\
\hline-49.8 & 59.8 & & 0.9640 & & 0.005635 \\
\hline-49.0 & 58.5 & 177.6 & 0.9620 & $\begin{array}{l}3.7899 \\
3.8075\end{array}$ & 0.005387 \\
\hline-45.7 & 56.2 & 177.65 & 0.9575 & 3.8075 & 0.005387 \\
\hline-38.2 & 51.5 & 177.75 & 0.9478 & 3.8467 & 0.004883 \\
\hline-32.6 & 47.9 & 177.8 & 0.9403 & 3.8874 & 0.004505 \\
\hline-21.0 & 42.6 & 178.0 & 0.9251 & 3.9411 & 0.003937 \\
\hline-13.6 & 39.8 & 178.1 & 0.9152 & 3.9838 & 0.003637 \\
\hline 0.0 & 35.8 & 178.35 & 0.8972 & 4.0636 & 0.003202 \\
\hline 9.3 & 33.2 & 178.5 & 0.8849 & 4.1202 & 0.002927 \\
\hline
\end{tabular}

The equation of the viscosity curve, $u_{t}=u_{0} /\left(1+A t+B t^{2}\right)$ was solved, using values of viscosity obtained from the curve. The value of $A$ was found to be 0.0094775 , and that of $B, 0.000011165$. The equation was differentiated and the temperatures at which the slope of the curve was 0.0000323 and 0.0000987 were found to be $-3.8^{\circ}$ and $-54.4^{\circ}$, respectively. From the equation, the viscosity at $-54.4^{\circ}$ was found to be 0.00616 , and that at $-3.8^{\circ}, 0.00332$; these values are in very good agreement with the values obtained from the curve. The ratio of the viscosity at $-54.4^{\circ}$ to that at $-3.8^{\circ}$ was found to be $1.86 .^{\circ}$ The absolute viscosity at the boiling point was found on the curve to be 0.002895 , as compared to 0.002901 from the equation. The molecula: viscosity was calculated for the important values given in Table $V$.

The Critical Temperature of Ethylene Oxide.-The critical temperature, determined in the usual manter, was found to be $192^{\circ}$, the disappearance of the meniscus being very sharp.

9 Thorpe and Rogers, Phil. Trans., 185, 397 (1894). 


\begin{tabular}{ccc}
\multicolumn{3}{c}{ Table V } \\
Molectular Viscosity of Ethylene Oxide \\
Temp. & Absolute viscosity & Molecular viscosity \\
${ }^{\circ} \mathrm{C}$. & 0.002895 & \\
10.73 & 0.003200 & 0.03922 \\
0.0 & 0.003320 & 0.04290 \\
-3.8 & 0.006165 & 0.04434 \\
-54.4 & & 0.07851
\end{tabular}

The Physical Properties of Methyl Ether and Acetaldehyde.-In order to place the ethylene oxide in its relation to other oxygen-containing compounds, the physical properties of methyl ether, acetaldehyde, and ethyl alcohol were obtained from the literature. It was found that the data for the physical properties of the most important two, acetaldehyde and methyl ether, were very incomplete, and it was necessary to determine many of them. The surface-tension and density curves of both substances were determined, and in the case of methyl ether, the vapor-pressure curve also. The methyl ether was prepared in the ordinary manner from methyl alcohol and sulfuric acid, and was purified by passage over phosphorus pentoxide and by low temperature fractional distillation, as described for the preparation of ethylene oxide. A mixture of acetaldehyde and a small amount of its polymers was distilled from sulfuric acid and the liquid obtained, boiling at $28^{\circ}$, was again distilled. The distilling flask was placed in a water-bath maintained at $25^{\circ}$ to $30^{\circ}$ and acetaldehyde was condensed at a temperature of $18^{\circ}$, under a pressure of a few centimeters of mercury.

The experimental procedure in the determination of the physical properties was the same as used in the case of ethylene oxide. In Table III and Fig. 3 will be found the values of surface tension and molecular surface energy of the two substances; in Table II and Fig. 2 the densities of both are given; and in Table I and Fig. 1 are the vapor pressures of methyl ether. The methyl ether was found to have a boiling point of $-24.9^{\circ}$, and that of acetaldehyde was $20.8^{\circ}$.

Summary of the Physical Properties.-The physical constants of these substances are of interest because they show the extent to which they are affected by the constitutions of the molecules. In Table VI ethylene oxide is compared to acetaldehyde, ethyl alcohol and methyl ether. The oxygen in each of these compounds is linked in a different way, but the molecular weights are so nearly identical that the effect of linkage can be observed.

The ethereal oxygen is the most intensely saturated, as the methyl ether molecule is left with the smallest external attraction for its neighbor. This is evidenced by the fact that it has the lowest melting point, boiling point, critical temperature, latent heat of evaporation and Ramsay and Shields constant. The other 3 substances do not differ from one 
TABLE VI

\begin{tabular}{|c|c|c|c|c|}
\hline & $\begin{array}{l}\text { Ethylene } \\
\text { oxide }\end{array}$ & $\begin{array}{l}\text { Ethyl } \\
\text { alcohol }\end{array}$ & Acetaldehyde & $\begin{array}{l}\text { Methyl } \\
\text { ether }\end{array}$ \\
\hline Freezing point, ${ }^{\circ} \mathrm{C}$. & -111.3 & -114.0 & -124.6 & -138.0 \\
\hline Boiling point, ${ }^{\circ} \mathrm{C} \ldots \ldots \ldots$ & 10.73 & 78.3 & 20.8 & -24.9 \\
\hline Critical temperature, ${ }^{\circ} \mathrm{C} .$. & 192.0 & 240.6 & 181.5 & 129.6 \\
\hline $\begin{array}{l}\text { Molecular heat of evaporization } \\
(\text { Cal. } \ldots \ldots \ldots \ldots \ldots \ldots \ldots \ldots\end{array}$ & 6.00 & 8.95 & 6.01 & 5.31 \\
\hline$K-$ Ramsay and Shields........ & 1.79 & 1.18 & 1.41 & 2.00 \\
\hline Surface tension at the boiling point. & 25.8 & 17.6 & 21.1 & 18.6 \\
\hline Total surface energy............ & 73.1 & 46.0 & 56.6 & 55.1 \\
\hline $\begin{array}{l}\text { Molecular volume at the boiling } \\
\text { point..................... } \\
\text { Mclecular viscosity at slope }\end{array}$ & 49.9 & 62.5 & 56.4 & 62.7 \\
\hline $0.0000323 \ldots \ldots \ldots \ldots \ldots \ldots$ & 0.0412 & & 0.0448 & \\
\hline $\begin{array}{r}\text { Molecular viscosity at slope } \\
0.0000987 \ldots \ldots \ldots \ldots \ldots \ldots \ldots\end{array}$ & 0.0785 & 0.0933 & & \\
\hline
\end{tabular}

another to such a marked degree. The hydroxyl oxygen evidently gives rise to more definite association than any of the others; this continues into the higher temperatures, thus; giving the markedly larger latent heat of vaporization and higher boiling point, critical temperature and the lowest value of Ramsay and Shields constant. The most symmetrical molecule, that of ethylene oxide, has the highest freezing point.

The surface tension and molecular surface energy are in excellent agreement with the theory of orientation of Langmuir ${ }^{10}$ and Harkins. ${ }^{11}$ The ethyl alcohol, in which it is possible for the methyl group to be farthest away from the oxygen (the polar group), has by far the smallest value, approximating to a hydrocarbon surface. Next, the acetaldehyde and methyl ether, where the methyl groups are equidistant from the polar group, have almost identical values for the total surface energy, but values which are considerably greater than in the case of ethyl alcohol, as the polar group is nearer the surface and, as a result, the surface energy is greater. Ethylene oxide, with which a saturated hydrocarbon surface is impossible, has by far the greatest surface energy.

If definite values can be assigned to the volumes of atoms, it was pointed out by one of us, ${ }^{12}$ that Kopp's values and an increase for unsaturation are in the best agreement with experimental results. Taking 11 for carbon and 5.5 for hydrogen, hydroxyl, ketonic and ethereal oxygen have the values $7.5,12.4$, and 7.7 ; respectively, whereas the oxygen in ethylene oxide has the apparent value of 5.9 , additional evidence of the ring structure, which gives rise to a contraction. This, if taken into account, would give the correct value for the volume of the oxygen, obviously a larger one.

in Langmuir, This Journal, 39, 1848 (1917).

1 Harkins, ibid., 39, 541 (1917).

12 Ref. 7, p. 1106. 
The viscosity of ethylene oxide at equal slope is slightly less than that of acetaldehyde and much less than that of ethyl alcohol, indicating that the oxygen has probably a smaller effect than a carbonyl oxygen and that such a saturated ring has no effect, or a negative effect, in comparison with the large positive effect of an unsaturated ring formation. The constant 1.86 , mentioned previously, and the absolute viscosity divided by the square root of the density at the boiling point, ${ }^{13} 0.00309$, are results both of which point to polymerization. Arrhenius' constant ${ }^{14}$ is normal, being 1.2 , as would be expected from the fact that Trouton's constant has the normal value.

The values of the physical properties of ethylene oxide, compared with those of the other oxygen-containing compounds, are in close agreement with the constitution given to this substance. In assigning relative values to the external fields of the molecules from the consideration of physical properties, methyl ether stands out definitely, but the same cannot be said in comparing the other three. Another means by which it is hoped to be able to make the comparison will be referred to later.

Oxonium-compound Formation with Ethylene Oxide.-In order to determine the tendency of ethylene oxide toward oxonium-compound formation, the systems of ethylene oxide-chlorine - bromine - water -hydrogen bromide-hydrogen chloride were investigated.

The freezing-point curve of the system, ethylene oxide-chlorine, was obtained over the range $0 \%$ to $60 \%$ ethylene oxide by means of the usual experimental method. The chlorine was prepared in the ordinary way from potassium permanganate and hydrochloric acid, washed with water and then with conc. sulfuric acid. The ethylene oxide was kept in a capped pycnometer from which it was added to the liquid chlorine as required. Except during weighing, the pycnometer was placed in a mixture of solid carbon dioxide and ether to prevent evaporation, and when ethylene oxide was to be added to the chlorine the delivery tube was first cooled by a piece of cotton wool soaked in liquid air.

TABLE VII

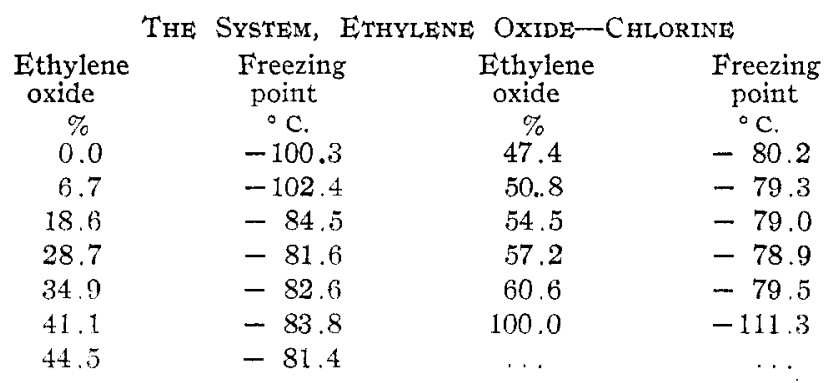

\footnotetext{
${ }^{13}$ Arrhenius, Medd. K. Vetenskapsakad. Nobelinst., 3, 22 (1918).

14 Ref. 13, no. 20.
} 
The freezing points obtained may be taken as correct to $0.2^{\circ}$ and the composition to $0.3 \%$. In Table VII will be found the values obtained, the results being plotted in Fig. 5 .

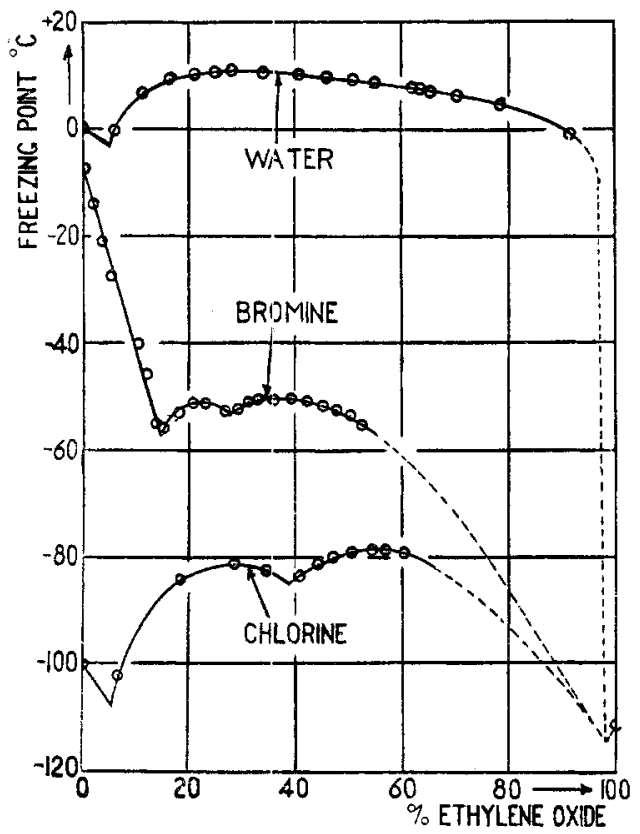

Fig. 5.

From the curve it will be seen that there are three eutectics, indicating the formation of two compounds corresponding to $\mathrm{C}_{2} \mathrm{H}_{4} \mathrm{O} . \mathrm{Cl}$ and $\mathrm{C}_{2} \mathrm{H}_{4} \mathrm{O} .3 \mathrm{Cl}$. The mixture of chlorine and ethylene oxide is exceedingly dangerous. The $30 \%$ mixture on being warmed to the neighborhood of $0^{\circ}$, exploded violently with the deposition of carbon and the formation of hydrogen chloride.

In the determination of the freezing-point curve of the system, ethylene oxide-bromine, different experimental methods were necessary in adding the ethylene oxide. A gas buret, filled with mercury and fitted with a 2-way stopcock, had one tube connected to a supply of pure liquid ethylene oxide, and the other tube drawn out to a fine capillary tube which ended in the bottom of the test-tube in which the determinations were to be made. A second capillary tube, fitted with a stopcock and connected to a dry air supply, was sealed to the first capillary tube near the buret. In order to add ethylene oxide to the test-tube, first the buret stopcock was opened to the capillary and the mercury raised until all the air was driven out. The stopcock was then opened to the ethylene oxide and ethylene oxide vapor was drawn in. Any amount of ethylene oxide up to $100 \mathrm{cc}$. at atmospheric pressure could be obtained at one time by altering the tem- 
perature around the ethylene oxide supply. The stopcock was then reversed and the ethylene oxide driven through the capillary tube by raising the mercury, and was condensed in the test-tube. Air was then blown through the capillary tube. The weight of ethylene oxide added could be calculated from the gas laws, the correction as determined in this work being used. The bromine was distilled once over anhydrous calcium bromide to remove any water present. The freezing points were determined in the usual way over the range tabulated in Table VIII and plotted in Fig. $\tilde{j}$.

\begin{tabular}{cccc}
\multicolumn{4}{c}{ Table VIII } \\
$\begin{array}{c}\text { The } \\
\text { Eithylene } \\
\text { oxide }\end{array}$ & $\begin{array}{c}\text { Freezing } \\
\text { point }\end{array}$ & $\begin{array}{c}\text { Ethylene } \\
\text { oxide }\end{array}$ & $\begin{array}{c}\text { Freezing } \\
\text { point }\end{array}$ \\
0.0 & ${ }^{\circ} \mathrm{C}$. & $\%$ & ${ }^{\circ} \mathrm{C}$. \\
1.8 & -7.3 & 29.4 & -52.5 \\
3.7 & -14.1 & 31.2 & -51.3 \\
5.4 & -21.2 & 33.0 & -50.9 \\
10.6 & -27.7 & 36.3 & -50.7 \\
12.3 & -40.2 & 39.3 & -50.8 \\
13.9 & -46.0 & 42.4 & -51.2 \\
15.4 & -55.2 & 45.3 & -52.0 \\
18.3 & -56.1 & 48.0 & -52.7 \\
20.9 & -53.1 & 50.4 & -53.7 \\
23.4 & -51.4 & 52.8 & -55.6 \\
27.1 & -51.4 & 100.0 & -11.3 \\
& -52.8 & $\ldots$. & $\ldots .$.
\end{tabular}

Three eutectic points are evident in this case, indicating the formation of the compounds $\mathrm{C}_{2} \mathrm{H}_{4} \mathrm{O} . \mathrm{Br}$ and $\mathrm{C}_{2} \mathrm{H}_{4} \mathrm{O} .2 \mathrm{Br}$. The final mixture of ethylene oxide and bromine was allowed to warm to room temperature and did not explode on standing, but after some time it became deep red, and a solid. This solid is probably the bromine compound referred to by Demole $^{15}$ and is not an oxonium compound, but is one due to an internal rearrangement of the atoms. The oxonium compound, practically colorless, exists only at low temperatures and, on being allowed to warm, changes to the red solid, stable at high temperatures.

The freezing-point curve of the system, ethylene oxide-water, was determined over the whole range. From $0 \%$ to $30 \%$ ethylene oxide, the same method was used as in the determination of the bromine curve, with distilled water in the place of bromine. From the $100 \%$ ethylene oxide side, a slightly different procedure was employed. A known volume, at a known pressure and temperature of ethylene oxide, was condensed in the test-tube, in the manner described, and the weight calculated. Distilled water was added, by means of a pycnometer, in the required

${ }^{15}$ Demole, Ber., 9, 47 (1876). 
amounts and the freezing points determined up to $70 \%$ of water. The values obtained are tabulated in Table IX and plotted in Fig. 5 .

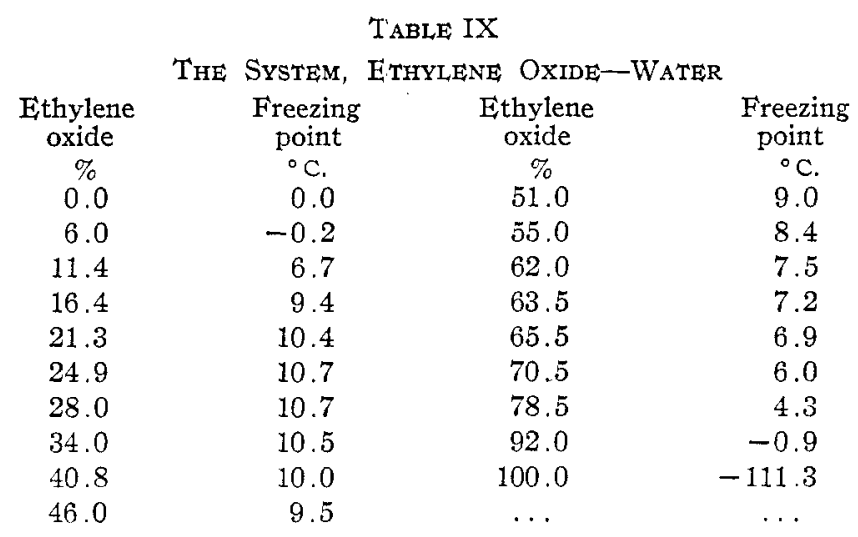

From the curve it is seen that there are two eutectics, indicating that only one compound is formed confirming the observation of Wurtz that a hydrate exists, the composition of which he was unable to determine. The formula of this compound is very indefinite, as the curve is so very flat. The compound lies, however, between $\mathrm{C}_{2} \mathrm{H}_{4} \mathrm{O} .5 \mathrm{H}_{2} \mathrm{O}$ and $\mathrm{C}_{2} \mathrm{H}_{4} \mathrm{O}$.$8 \mathrm{H}_{2} \mathrm{O}$, the probability being that it is $\mathrm{C}_{2} \mathrm{H}_{4} \mathrm{O} \cdot 6 \mathrm{H}_{2} \mathrm{O}$. It is of interest that when this mixture was kept in a sealed glass tube for several weeks the freezing point remained unchanged, showing that the ethylene oxide and water do not combine to form glycol to any extent.

The system, ethylene oxide-hydrogen bromide, was investigated in the same manner as was the chlorine system. The hydrogen bromide.was prepared in the usual way by dropping bromine onto red phosphorus covered with water. The gas was dried by passage over phosphorus pentoxide and condensed in the test-tube in which the freezing point determinations were to be made. Upon addition of the ethylene oxide, a vigorous reaction occurred with the formation of ethylene bromohydrin. This reaction took place even when the hydrogen bromide was at liquid air temperature and the ethylene oxide was at $-78^{\circ}$, when added. It was noticed, however, that small traces of a yellow solid existed momentarily on the sides of the tube where the ethylene oxide first came in contact with the acid, but on warming up this solid until it melted, it immediately disappeared and could not be recovered.

Under the belief that small traces of water aided the bromohydrin formation, another method that had met with success in other cases, ${ }^{16}$ was used. It used an apparatus free from air, by means of which required arnounts of the two gases could be condensed in a small bulb which could be then sealed off and the freezing point of the mixture in it de-

${ }^{16}$ Maass and Russell, 'THIS Jour.yaL, 40, 1565 (1918). 
termined. The hydrogen bromide was prepared as before and dried very carefully by repeated distillation over phosphorus pentoxide. A known volume was condensed in the bulb and then a known volume of ethylene oxide condensed on top of the acid by means of liquid air so that both constituents were solid. It was found in every case, as soon as the bulb was warmed sufficiently to melt either of the materials, that a reaction took place with the formation of the bromohydrin. These bulbs on being opened were found to contain the bromohydrin in all cases, together with either free ethylene oxide or the free acid, depending on which was present in excess of the equimolecular quantity. The yellow solid, noticed before, was also formed here and behaved in the same manner. This compound was probably the equimolecular oxonium compound corresponding to the compound $\left(\mathrm{C}_{2} \mathrm{H}_{5}\right)_{2} \mathrm{O} . \mathrm{HBr}$ found in the system, ethyl ether-hydrogen bromide. ${ }^{17}$

Since hydrogen chloride has a lower melting point than hydrogen bromide, it is possible to mix the liquids at lower temperatures, and it was thought that thus the oxonium compound might be isolated. The hydrogen chloride was obtained from the concentrated solution and dried by repeated distillations over phosphorus pentoxide. On attempting to obtain the freezing-point curve by the bulb method, it was found that the chlorohydrin always formed and there was no indication of any compound analgous to the unstable yellow compound found in the case of the hydrogen bromide.

Summary of the Oxonium-Compound Formation.-Previous work on halogen addition to oxygen compounds at low temperatures to form oxonium compounds has shown that an hydroxyl oxygen adds one halogen atom, and ketonic and ethereal oxygens add two halogen atoms. Unfortunately, there are not enough data available to enable one to state that this rule is without exception. In the case of ethylene oxide, as was shown, two compounds are formed with chlorine and also with bromine of the respective formulas, $\mathrm{C}_{2} \mathrm{H}_{4} \mathrm{O} . \mathrm{Cl}, \mathrm{C}_{2} \mathrm{H}_{4} \mathrm{O} . \mathrm{Cl}_{3}, \mathrm{C}_{2} \mathrm{H}_{4} \mathrm{O} . \mathrm{Br}$, and $\mathrm{C}_{2} \mathrm{H}_{4} \mathrm{O} \cdot \mathrm{Br}_{2}$. As far as is known, this is quite different from the behavior of the common types of oxygen mentioned and serves to show the peculiar nature of the linkages involved. In previous work, all oxygen compounds forming oxonium compounds with the halogens contained methyl groups, and as ethylene oxide contains no methyl groups it is evident that the presence of methyl groups is not necessary to oxonitum compound formation.

The investigation of the behavior of ethylene oxide with the halogen acids serves to show the activity of ethylene oxide and in particular the ease with which the ring is broken and the large amount of energy liberated in the process. The formation of bromohydrin probably passes ${ }_{17}$ McIntosh, Tnis Journal, 33, 71 (1911). 
through an intermediate stage where an addition compound is formed which immediately breaks down, the existence of which was indicated by the yellow solid observed. The decomposition of this compound is probably assisted by the presence of traces of water; and it is possible that, with further precautions toward the elimination of water, this compound might be isolated in quantity and its composition determined.

The Vapor-density Measurements.-The vapor density of ethylene oxide was measured at various temperatures and pressures. The interest attached to these experiments from the point of view of ethylene oxide was not the incentive for undertaking this work but, as was pointed out in the introduction, these determinations are but the first of similar experiments involving a large number of other compounds. The choice of ethylene oxide as the first was due to chance; its properties were being examined and a large amount of the purified material was available. The importance attached to the vapor-density determinations at low pressures and at temperatures approaching the boiling point lies in the fact that from them deductions can be made as to the relative magnitude of molecular attractions. What is determined corresponds in a way to that which is involved in the constant $a$ of van der Waal's equation. It was brought to the authors' attention after the work had started that J. J. Thomson in his book "The Corpuscular Theory of Matter" 18 emphasized the bearing measurements of this kind would have in giving an indication of the relative attractions of acetylene, ethylene, and ethane molecules for one another.

The method of determining the vapor densities is one which has been described in detail in THIS JouRNAL. ${ }^{19}$ A perfectly evacuated flask of about 1.2 liters capacity is filled with the pure gas to a definite pressure at a definite temperature. The gas is condensed in a small glass bulb which is sealed off and weighed at ordinary temperatures. Great accuracy can be obtained even for density measurements at low pressures as the error of the 'dead space' is eliminated as described in the original paper. All pressures, measured in centimeters of mercury, are corrected to $0^{\circ}$ and the weights corrected for air displacement.

For the initial tabulation of the experimental results it seemed best to calculate the molecular weights from the simple gas-law equation, and plot these values against the pressure. The graphic extrapolation of such isothermal curves should give for zero pressure the theoretical molecular weight of the gas. At the same time the magnitude of $\mathrm{d} M / \mathrm{d} P$ gives an indication of the molecular attraction since both temperatures and pressures are relatively low. The following

${ }^{18}$ Thomson, "The Corpuscular Theory of Matter," Constable and Co., Ltd., 1907 , p. 132.

${ }^{19}$ Ref. 16, p. 1847. 
values were obtained at temperatures considerably above the boiling point.

$\begin{array}{cccc}\begin{array}{c}\text { Temp. } \\ { }^{\circ} \mathrm{C} .\end{array} & \begin{array}{c}\text { Press. } \\ \text { Cm. of } \mathrm{Hg}\end{array} & \begin{array}{c}\text { Molecular } \\ \text { weight }\end{array} & \mathrm{d} M / \mathrm{d} P \\ 31.5 & 55.97 & 44.89 & 0.01608 \\ & 28.56 & 44.45 & \\ 39.3 & 76.23 & 44.94 & 0.01193 \\ & 38.33 & 44.49 & \\ 96.4 & 77.30 & 44.59 & 0.00686 \\ & 39.27 & 44.33 & \end{array}$

These results are represented graphically in Fig. 6 and the values for $M$ at zero pressure are $44.00,44.03$ and 44.06 , all within $0.1 \%$ of the theoretical value of 44.04 . This agreement proves the claim for the purity of the ethylene oxide and the accuracy of the vapor-density measurements to be well founded.

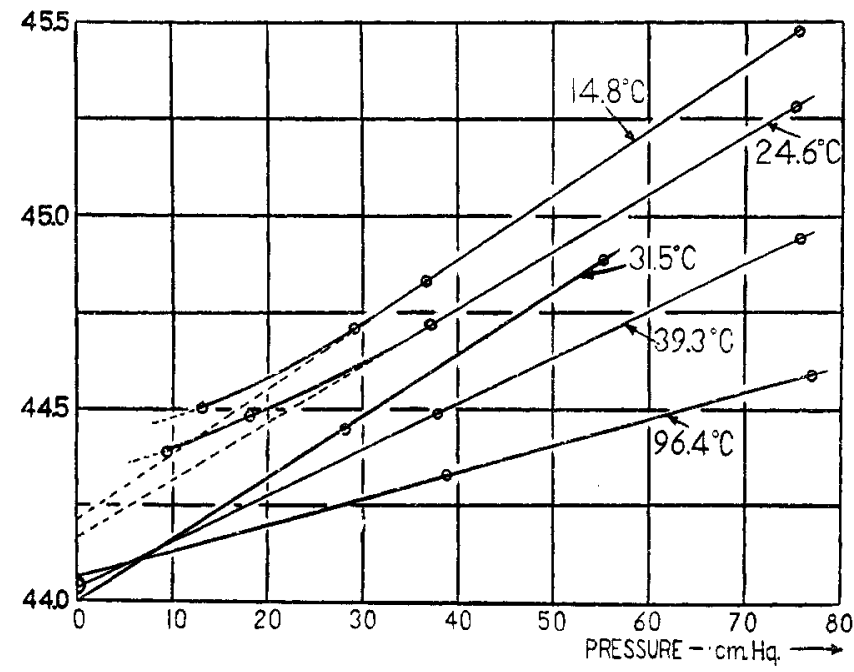

Fig. 6.

When vapor-density measurements were made at temperatures nearer the boiling point, the results obtained gave curves of a somewhat different type, as can be seen by examining the curves representing the results at $14.8^{\circ}$ and $24.6^{\circ}$ in Fig. 6.

This was not due to the contamination of the ethylene oxide by an impurity, as these determinations were made at the same time and with the same material as those at the higher temperatures. A fresh sample gave the same results. Extrapolating the apparent molecularweight values at 75.85 and $38.96 \mathrm{~cm}$. for $14.8^{\circ}$, the molecular weight at zero pressure is 44.20 , which differs from the theoretical by an amount many times greater than any possible experimental error. It was thought 


$\begin{array}{cccc}\begin{array}{c}\text { Temp. } \\ \text { o C. }\end{array} & \begin{array}{c}\text { Press. } \\ \text { Cm. of } \mathbf{H g}\end{array} & \begin{array}{c}\text { Molecular } \\ \text { weight }\end{array} & \mathrm{d} M / \mathrm{d} P \\ 14.8 & 75.85 & 45.48 & 0.01688 \\ & 38.96 & 44.86 & \\ & 29.50 & 44.71 & \\ & 13.42 & 44.50 & \\ 24.6 & 76.56 & 45.28 & 0.01436 \\ & 37.54 & 44.72 & \\ & 18.43 & 44.48 & \\ & 9.90 & 44.39 & \end{array}$

that this might be due to a slight amount of polymerization. If this were the case, the values obtained at still lower pressures should gradually diminish to the theoretical value, but as is seen by those taken at 29.50 and $13.42 \mathrm{~cm}$. the reverse is the case. As an increase in association with diminished pressure seems impossible, another explanation for these results has to be considered. The pressures are measured by a mercury manometer and the intrinsic properties of the mercury may come into play or adsorption might take place on the glass surfaces at the lower temperatures. These are two possible causes of the results obtained.

That adsorption might give rise to the values of $M$ which are too great and which increase at lower pressures can be seen by considering the general form of an adsorption curve $S=K P^{1 / n}$ where $S$ is the quantity adsorbed and the constants have values such that at fairly low pressures $S$ does not increase to any great extent with further increase in the pressure, $P$. A further test of the experimental values obtained at $14.8^{\circ}$ was made by condensing the gas down to a pressure intermediate between the initial pressure and zero pressure. When this is done, then the apparent molecular weight obtained by experiment is given by the equation $M=\frac{\left(P_{1}-P_{2}\right) V}{m R T}$ where $P_{1}$ is the initial pressure and $P_{2}$ the final pressure, and $M$ should also be identical with molecular weight calculated from the values already obtained $^{20}$ to be,

$$
\frac{M_{1} P_{1}-M_{2} P_{2}}{P_{1}-P_{2}}
$$

where $M_{1}$ is the apparent molecular weight at $P_{1}$ and $M_{2}$ is the apparent molecular weight at $P_{2}$ as read from the curve in Fig. 6. In a particular

${ }^{20}$ In the equation, $M=\frac{\left(P_{1}-P_{2}\right) V}{m R T}$, the weight $m$ may be replaced by $\left(m_{1}-m_{2}\right)$ where $m_{1}$ is the total weight of the gas at the original pressure $P_{1}$ and $m_{2}$ is the weight of the residual gas at a pressure $P_{2}$. From the general gas equation, $m_{1}$ and $m_{2}$ equal, respectively, $\frac{M_{1} P_{1} V}{R T}$ and $\frac{M_{2} P_{2} V}{R T}$, and on substitution of these values in the first equation the new equation $\frac{M_{1} P_{1}-M_{2} P_{2}}{P_{1}-P_{2}}=M$ is obtained. 
case the initial pressure $P_{1}$ was $78.09 \mathrm{~cm}$., the final pressure $P_{2}$ was 38.72 and the molecular weight calculated to be 46.19. From the graph, $M_{1}$ at $P_{1}$ was 45.52 and $M_{2}$ at $P_{2}$ was $44.8 \dot{6}$, giving a value for $M$ over the range $P_{1}-P_{2}$ of 46.17 , which is in close agreement with that found experimentally, thus corroborating the curve at $14.8^{\circ}$ represented in Fig. 6. These experiments at the lower temperatures will be repeated with the mercury manometer replaced by a glass spiral manometer so that the pressures may be measured without allowing the ethylene oxide to come into direct contact with the mercury.

Vapor-density measurements similar to those described above have been carried out with methyl ether, propylene and acetylene; and ethane, propane, ethylene, acetone and alcohol are being investigated. When these have been completed the values obtained for ethylene oxide will be referred to again and the relation between $\mathrm{d} M / \mathrm{d} P$ and molecular attraction fully examined.

\section{Summary}

The preparation and purification of ethylene oxide has been described and its properties examined. The vapor pressure, boiling point, melting point, surface tension, critical temperature, viscosity and density of the liquid have been determined and these physical constants compared to those of methyl ether, ethyl alcohol and acetaldehyde for which substances the missing data were also found experimentally. The particularly good agreement of the surface-tension data with the modern theory was pointed out. The physical properties of ethylene oxide bring out the ring structure of this compound as compared with the other three. The investigation of oxonium-compound formation gave evidence of the probable existence of a compound with hydrogen bromide. Bromine and chlorine form definite compounds at low temperatures which react at higher temperatures, an interatomic rearrangement taking place. The system with water showed the existence of a hydrate containing 7 or 8 molecules of water. The vapor density of ethylene oxide over the temperature range $14^{\circ}$ to $100^{\circ}$ and pressure range 0 to 1 atmosphere was measured, and it was pointed out that these measurements are the first of a series to be carried out with a number of other compounds, with the object of obtaining data on the relative molecular attraction.

Montreal, Canada 